\title{
Effects of growth conditions on biofilm formation by Actinobacillus pleuropneumoniae
}

\author{
Josée Labrie $^{1}$, Geneviève Pelletier-JacQues ${ }^{1}$, Vincent Deslandes ${ }^{1}$, \\ Mahendrasingh RAmJEET ${ }^{1}$, Eliane AugER ${ }^{1}$, John H.E. NASH ${ }^{2}$, Mario JACQUES ${ }^{1 *}$ \\ ${ }^{1}$ Groupe de recherche sur les maladies infectieuses du porc et Centre de recherche en infectiologie porcine, \\ Faculté de médecine vétérinaire, Université de Montréal, 3200 Sicotte, St-Hyacinthe, Québec, Canada J2S 7C6 \\ ${ }^{2}$ Office of Biotechnology, Genomics and Population Health, Public Health Agency of Canada, Ottawa, Ontario, \\ Canada K1A 0K9
}

(Received 24 April 2009; accepted 8 September 2009)

\begin{abstract}
Biofilm formation is an important virulence trait of many bacterial pathogens. It has been reported in the literature that only two of the reference strains of the swine pathogen Actinobacillus pleuropneumoniae, representing serotypes $5 \mathrm{~b}$ and 11 , were able to form biofilm in vitro. In this study, we compared biofilm formation by the serotype 1 reference strain S4074 of A. pleuropneumoniae grown in five different culture media. We observed that strain S4074 of A pleuropneumoniae is able to form biofilms after growth in one of the culture conditions tested brain heart infusion (BHI medium, supplier B). Confocal laser scanning microscopy using a fluorescent probe specific to the poly-N-acetylglucosamine (PGA) polysaccharide further confirmed biofilm formation. In accordance, biofilm formation was susceptible to dispersin B, a PGA hydrolase. Transcriptional profiles of A. pleuropneumoniae S4074 following growth in BHI-B, which allowed a robust biofilm formation, and in BHI-A, in which only a slight biofilm formation was observed, were compared. Genes such as tadC, tadD, genes with homology to autotransporter adhesins as well as genes $p g a A B C$ involved in PGA biosynthesis and genes involved in zinc transport were up-regulated after growth in BHI-B. Interestingly, biofilm formation was inhibited by zinc, which was found to be more present in BHI-A (no or slight biofilm) than in BHI-B. We also observed biofilm formation in reference strains representing serotypes 3, 4, 5a, 12 and 14 as well as in 20 of the 37 fresh field isolates tested. Our data indicate that $A$. pleuropneumoniae has the ability to form biofilms under appropriate growth conditions and transition from a biofilm-positive to a biofilm-negative phenotype was reversible.
\end{abstract}

Actinobacillus pleuropneumoniae / biofilm / growth condition / transcriptomic

\section{INTRODUCTION}

Actinobacillus pleuropneumoniae, a member of the Pasteurellaceae, is an important swine pathogen responsible for economic losses in the swine industry. To date, 15 sero-

\footnotetext{
* Corresponding author: mario.jacques@umontreal.ca
}

types of $A$. pleuropneumoniae have been described based on capsular antigens [3, 10]. The virulence of the bacteria is mediated by the coordinated action of several virulence factors, namely the capsule, lipopolysaccharides (LPS), Apx toxins and outer membrane proteins involved in iron uptake $[4,11,14,18$, 19, 28, 29].

It is widely accepted that the majority of bacteria in virtually all ecosystems (natural, 
engineered and pathogenic ecosystems) grow in matrix-enclosed biofilms [7]. The matrix provides biofilm cells with a protected microenvironment containing nutrients, secreted enzymes and DNA. The matrix also contributes to the increased resistance to antibiotics and host defenses exhibited by biofilm cells [15]. All members of the Pasteurellaceae are inhabitants of mucosal surfaces of mammals and therefore formation of a biofilm may be crucial to their persistence in vivo. However, biofilms have only been investigated in a few species of the Pasteurellaceae family [16]. In A. pleuropneumoniae, the formation of biofilms on polystyrene microtiter plate is dependent on the production of poly-N-acetylglucosamine (PGA) a linear polymer of $\mathrm{N}$-acetylglucosamine residues in $\beta(1,6)$ linkage $[17,20]$. The production of PGA is encoded by the genes pgaABCD [20]. A novel insertion element, ISApl1, was recently identified in an $\mathrm{A} / \mathrm{T}$ rich region of the $p g a C$ gene of the biofilm-negative A. pleuropneumoniae strain HB04 [25]. PGA is a substrate for dispersin B (DspB), a biofilm-releasing glycosyl hydrolase produced by Aggregatibacter (Actinobacillus) actinomycetemcomitans and A. pleuropneumoniae [20, 22]. It has also been reported that only 2 of the $15 \mathrm{~A}$. pleuropneumoniae reference strains, representing serotypes $5 \mathrm{~b}$ and 11 , were able to form a biofilm in vitro and that the transition from a biofilm-positive to biofilm-negative phenotype was irreversible [21]. However, Li et al. [24] recently observed slight biomass of biofilm when the A. pleuropneumoniae serotype 1 reference strain S4074 was grown in serum-free TSB but not in serum-containing TSB. In addition, an enhanced biofilm formation was observed in luxS [24] and hns [8] mutants of $A$. pleuropneumoniae strain S4074.

The aims of the present study were: (i) to re-evaluate biofilm formation by $A$. pleuropneumoniae reference strain S4074 (serotype 1) under different growth conditions using a standard microtiter plate and crystal violet staining protocol; (ii) to evaluate the ability of 16 reference strains and 37 fresh field isolates to form biofilm in the growth condition shown to allow the best biofilm formation and (iii) to determine the transcriptomic profile of A. pleuropneumoniae strain S4074 when grown in that culture condition.

\section{MATERIALS AND METHODS}

\subsection{Bacterial strains and growth conditions}

Bacterial strains used in the present study are listed in Table I. Bacteria were grown on brain heart infusion agar plates (BHI; Difco Laboratories, Detroit, MI, USA) supplemented with $15 \mu \mathrm{g} / \mathrm{mL}$ nicotinamide adenine dinucleotide (NAD). A colony was transferred into $5 \mathrm{~mL}$ of Luria-Bertani broth (LB; Difco), tryptic soy broth (TSB; Difco), Mueller Hinton broth (MH; Difco) or BHI (BHI-A; Difco or BHI-B; Oxoid Ltd, Basingstoke, Hampshire, UK) with $5 \mu \mathrm{g} / \mathrm{mL}$ NAD and incubated at $37^{\circ} \mathrm{C}$ overnight with agitation. This culture was used for the biofilm assays.

\subsection{Biofilm assay in microtiter plates}

The microtiter plate biofilm assay is a static assay particularly useful for examining early events in biofilm formation [27]. The wells of a sterile 96-well microtiter plate $\left(\right.$ Costar $^{\circledR}$ 3599, Corning, NY, USA) were filled in triplicate with a dilution $(1 / 100)$ of an overnight bacterial culture. Following an incubation of 6 or $24 \mathrm{~h}$ at $37^{\circ} \mathrm{C}$, the wells were washed by immersion in water and excess water was removed by inverting plates onto a paper towel. The wells were then filled with $100 \mu \mathrm{L}$ of crystal violet $(0.1 \%)$ and the plate was incubated for $2 \mathrm{~min}$ at room temperature. After removal of the crystal violet solution, the plate was washed and dried in a $37^{\circ} \mathrm{C}$ incubator for $30 \mathrm{~min}$ and $100 \mu \mathrm{L}$ of ethanol $(70 \%)$ were added to the wells. Absorbance was measured at $590 \mathrm{~nm}$ using a spectrophotometer (Powerwave, BioTek Instruments, Winooski, VT, USA).

\subsection{Scanning laser confocal microscopy}

The same biofilm assay protocol was used as described previously. After the 6 or $24 \mathrm{~h}$ incubation, the wells were filled with $100 \mu \mathrm{L}$ of Wheat Germ Agglutinin (WGA)-Oregon Green 488 (Molecular Probes, Eugene, OR, USA) diluted $1 / 100$ in PBS and the plate was incubated for $30 \mathrm{~min}$ at room temperature in the dark. The plate was then washed with water and filled with PBS. The plate was observed with a confocal microscope (Olympus FV1000 
Table I. A. pleuropneumoniae strains used in the present study.

\begin{tabular}{|c|c|c|}
\hline Strains & Relevant traits & Source \\
\hline \multicolumn{3}{|l|}{ Reference strains } \\
\hline S4074 & Serotype 1 & K.R. Mittal ${ }^{1}$ \\
\hline 4226 & Serotype 2 & K.R. Mittal ${ }^{1}$ \\
\hline 1421 & Serotype 3 & K.R. Mittal ${ }^{1}$ \\
\hline 1462 & Serotype 4 & K.R. Mittal ${ }^{1}$ \\
\hline K17 & Serotype $5 \mathrm{a}$ & K.R. Mittal ${ }^{1}$ \\
\hline L20 & Serotype $5 b$ & K.R. Mittal ${ }^{1}$ \\
\hline FEMO & Serotype 6 & K.R. Mittal ${ }^{1}$ \\
\hline WF.83 & Serotype 7 & K.R. Mittal ${ }^{1}$ \\
\hline 405 & Serotype 8 & K.R. Mittal ${ }^{1}$ \\
\hline 13261 & Serotype 9 & K.R. Mittal ${ }^{1}$ \\
\hline 13039 & Serotype 10 & K.R. Mittal ${ }^{1}$ \\
\hline 56153 & Serotype 11 & K.R. Mittal ${ }^{1}$ \\
\hline 832985 & Serotype 12 & K.R. Mittal ${ }^{1}$ \\
\hline $\mathrm{N} 273^{4}$ & Serotype 13 & M. Gottschalk ${ }^{1}$ \\
\hline $3906^{4}$ & Serotype 14 & M. Gottschalk ${ }^{1}$ \\
\hline HS143 & Serotype 15 & M. Gottschalk ${ }^{1}$ \\
\hline \multicolumn{3}{|l|}{ Field strains } \\
\hline $05-7430,05-7431$ & Serotype 1 & M. Ngeleka ${ }^{2}$ \\
\hline $111 \mathrm{~A}, 719,2398,2521$ & Serotype 1 & D. Slavic ${ }^{3}$ \\
\hline $05-4817,05-C 996,06-996$ & Serotype $5 \mathrm{a}$ & S. Messier ${ }^{1}$ \\
\hline $04-37943,04-3128,05-508$ & Serotype $5 \mathrm{a}$ & M. Ngeleka ${ }^{2}$ \\
\hline $05-6501,06-4091$ & Serotype $5 b$ & S. Messier ${ }^{1}$ \\
\hline $03-14796,03-22382,03-22383,05-4832$ & Serotype $5 \mathrm{~b}$ & M. Ngeleka ${ }^{2}$ \\
\hline $366 \mathrm{~A}, 400,564 \mathrm{D}, 888$ & Serotype $5 b$ & D. Slavic ${ }^{3}$ \\
\hline $05-3695,06-3008,06-3060,06-4108$ & Serotype 7 & S. Messier ${ }^{1}$ \\
\hline $04-37257,05-14401$ & Serotype 7 & M. Ngeleka ${ }^{2}$ \\
\hline $881,986,1951,4648$ & Serotype 7 & D. Slavic ${ }^{3}$ \\
\hline $05-13146,05-14657,05-20080,05-20081,05-2983$ & Serotype 15 & M. Ngeleka ${ }^{2}$ \\
\hline
\end{tabular}

${ }^{1}$ Faculté de médecine vétérinaire, Université de Montréal, St-Hyacinthe, QC, Canada.

${ }^{2}$ Prairie Diagnostic Services, University of Saskatchewan, Saskatoon, SK, Canada.

${ }^{3}$ Ontario Veterinary College, University of Guelph, Guelph, ON, Canada.

${ }^{4}$ These strains are NAD-independent and belong to biotype II.

IX81). WGA was excited at $488 \mathrm{~nm}$ and detected using $520 \mathrm{~nm}$ filters. The images were processed using Fluoview software (Olympus).

\subsection{Transcriptomic microarray experiments}

\subsubsection{RNA extractions}

For the microarray experiments, BHI-A or BHIB broths were inoculated with $500 \mu \mathrm{L}$ of an overnight culture of $A$. pleuropneumoniae serotype 1 strain S4074 and grown at $37^{\circ} \mathrm{C}$ in an orbital shaker until an optical density of 0.6 was reached. Ice-cold RNA degradation stop solution (95\% ethanol, $5 \%$ buffer-saturated phenol), shown to effectively prevent RNA degradation and therefore preserve the integrity of the transcriptome [2], was added to the bacterial culture at a ratio of $1: 10(\mathrm{vol} / \mathrm{vol})$. The sample was mixed by inversion, incubated on ice for $5 \mathrm{~min}$, and then spun at $5000 \mathrm{~g}$ for $10 \mathrm{~min}$ to pellet the cells. Bacterial RNA isolation was then carried out using the QIAGEN RNeasy MiniKit (QIAGEN, Mississauga, ON, Canada), as prescribed by the manufacturer. During the extraction, samples were subjected to 
an on-column DNase treatment, as suggested by the manufacturer and then treated with Turbo DNase (Ambion, Austin, TX, USA) to ensure that all DNA contaminants were eliminated. The RNA concentration, quality and integrity were assessed spectrophotometrically and on gel.

\subsubsection{Microarray construction and design}

For the construction of AppChip2, 2033 ORFs from the complete genome sequence of A. pleuropneumoniae serotype $5 \mathrm{~b}$ strain L20, representing more than $95 \%$ of all ORFs with a length greater than $160 \mathrm{nt}$, were amplified and spotted in duplicate on the chip. Spotted sheared genomic DNA from A. pleuropneumoniae L20 and porcine DNA are used as controls (GEO: GPL6658). Additional information concerning chip production is described by Gouré et al. [13].

\subsubsection{Microarray hybridizations}

cDNA synthesis and microarray hybridizations were performed as described [6]. Briefly, equal amounts $(15 \mu \mathrm{g})$ of test RNA and control RNA were used to set up a standard reverse transcription reaction using random octamers (BioCorp, Montreal, QC, Canada), SuperScript II (Invitrogen, Carlsbad, CA, USA) and aminoallyl-dUTP (Sigma, St. Louis, MO, USA), and the resulting cDNA was indirectly labelled using a monofunctional NHS-ester Cy3 or Cy5 dye (Amersham, Buckinghamshire, UK). The labelling efficiency was assessed spectrophotometrically. Labelled samples were then combined and added to the AppChip2 for overnight hybridization. Five hybridizations were performed for the serotype 1 strain S4074 BHI-A versus BHI-B experiments. All slides were scanned using a Perkin-Elmer ScanArray Express scanner.

\subsubsection{Microarray analysis and bioinformatics}

Microarray data analysis was conducted with the TM4 Suite of software from the J. Craig Venture Institute [30] as described by Deslandes et al. [9]. Briefly, raw data was first generated using SpotFinder v.3.1.1. Locally weighted linear regression (lowess) was then performed in the Microarray Data Analysis System (MIDAS) in order to normalize the data. The Significance Analysis of Microarray (SAM) algorithm [33], which is implemented in TIGR Microarray Expression Viewer (TMEV), was used to generate a list of differentially expressed genes.
During SAM analysis, a false discovery rate (FDR) of $0 \%$ was estimated for the serotype 1 strain S4074 BHI-A versus BHI-B experiments.

\subsection{Effects of DspB and zinc on biofilm formation}

Biofilms were grown for 6 or $24 \mathrm{~h}$ in BHI-B as described above. The wells were washed with water and then filled with $100 \mu \mathrm{L}$ of PBS containing 0.2, 2.0 or $20 \mu \mathrm{g} / \mathrm{mL}$ of DspB (Kane Biotech Inc, Winnipeg, MB, Canada) as described by Izano et al. [17]. After incubation at $37{ }^{\circ} \mathrm{C}$ for $5 \mathrm{~min}$, the wells were rinsed with water and stained with crystal violet. To monitor the effect of zinc on biofilm formation, bacteria were grown for 6 or $24 \mathrm{~h}$ in BHI-B supplemented with $50-250 \mu \mathrm{g} / \mathrm{mL}$ of $\mathrm{ZnCl}_{2}$.

\subsection{Statistical analysis}

The statistical significance ( $p$ value) of differences in biofilm phenotypes (mean optical density values) was determined by a paired, one-tailed $t$-test using GraphPad Prism version 4.0 (GraphPad Software, San Diego, CA, USA).

\section{RESULTS}

\subsection{Biofilm formation and growth conditions}

The ability of the A. pleuropneumoniae serotype 1 reference strain S4074 to form biofilms was evaluated using different growth media (Fig. 1). No biofilm was present in the wells containing bacterial cells grown in LB broth while only a slight biofilm was observed in wells containing cells grown in TSB, MH or BHI-A broths after $24 \mathrm{~h}$ of incubation. However a pronounced biofilm $(p<0.01)$ was formed when strain S4074 was grown in $\mathrm{BHI}-\mathrm{B}$ broth. This was not due to an increased growth in BHI-B compared to BHI-A as similar growth curves were observed in both media.

We then evaluated biofilm formation by all the reference strains of $A$. pleuropneumoniae after growth for 6 or $24 \mathrm{~h}$ in BHI-B. Similarly to what was observed with the serotype 1 , we found that growth in BHI-B, but not BHI-A, allows biofilm formation in reference strains representing serotypes 4 , 5a and 14 . In addition 


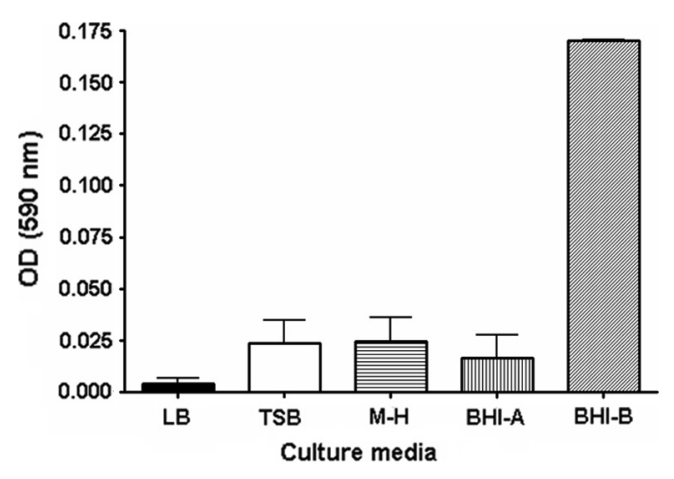

Figure 1. Biofilm formation by A. pleuropneumoniae serotype 1 reference strain S4074 grown in different culture media using the crystal violet staining protocol described in Materials and methods. LB: Luria-Bertani; TSB: tryptic soy broth; M-H: Mueller Hinton; BHI: brain heart infusion.

to the already reported biofilm formation in serotypes $5 \mathrm{~b}$ and 11 , we also observed biofilms for serotype 3 and 12 reference strains. Moreover, biofilm formation $\left(\mathrm{OD}_{590 \mathrm{~nm}}>0.1\right)$ was observed in $20(54 \%)$ of the 37 fresh field isolates of serotypes 1, 5, 7 and 15 that were tested (Fig. 2). In general, serotypes 5a, 5b and 7 field isolates tend to form more biofilms (mean OD of $1.15,1.47$ and 1.47 after $24 \mathrm{~h}$ ) than isolates from serotypes 1 and 15 (mean OD of 0.36 and 0.80 after $24 \mathrm{~h}$ ).

When A. pleuropneumoniae strain S4074 grown in BHI-A (no or slight biofilm) was transferred to BHI-B we observed the formation of a pronounced biofilm $(p<0.05)$. When these cells were then transferred back to BHIA, the phenotype returned to a slight biofilm $(p<0.05)$. This was also observed with field isolates representing different serotypes (data not shown).

\subsection{Scanning laser confocal microscopy}

We observed that for many reference strains, including strain S4074, and field isolates, pronounced biofilms were present after a short incubation period of only $6 \mathrm{~h}$ (Fig. 2). The biofilm was visualized by confocal laser scanning microscopy using a fluorescent probe
(WGA-Oregon Green) specific to the PGA matrix polysaccharide (Fig. 3). It is evident from these micrographs that A. pleuropneumoniae strain S4074 does not form biofilm when grown in BHI-A while a thick PGA matrix is formed by $A$. pleuropneumoniae serotype $5 \mathrm{~b}$ strain L20 grown in the same condition. However, both strains showed a pronounced biofilm when grown in BHI-B. In the case of strain $\mathrm{S} 4074$, the biofilm is even more important after $6 \mathrm{~h}$ than $24 \mathrm{~h}$ of incubation (Fig. 3). Because scanning laser confocal microscopy allows optical sectioning of the biofilm either in the horizontal or the vertical dimension it is possible to evaluate the thickness of the biofilm. We evaluated the thickness of $A$. pleuropneumoniae strain S4074 biofilm to be of $\sim 25 \mu \mathrm{m}$ after growth in BHI-B for $6 \mathrm{~h}$ (Fig. 3C) and even greater $(\sim 65 \mu \mathrm{m})$ for $A$. pleuropneumoniae strain L20.

\subsection{Transcriptomic profiling under different growth conditions}

To assess the transcriptional response of A. pleuropneumoniae $\mathrm{S} 4074$ after growth in BHI-B compared to BHI-A, transcript profiling experiments using DNA microarrays were performed. Overall, 232 genes were significantly differentially expressed during growth in BHIB; 152 being up-regulated and 80 being down-regulated (Tab. II). The genes that showed the highest level of up-regulation after growth in BHI-B belonged to the "amino acid biosynthesis", "energy metabolism", "transport and binding proteins", "cell envelope" and "hypothetical/unknown/unclassified" functional classes (Fig. 4). Genes such as tadC and tadD (tight adherence proteins $\mathrm{C}$ and $\mathrm{D}$ ), genes with homology to autotransporter adhesins (APL 0443 and APL 0104) as well as genes pga $\bar{B} \bar{B}$ involved in PGA biosynthesis were up-regulated after growth in BHI-B. A cluster of genes involved in dipeptide transport $(d p p A B C D F)$ and genes involved in the synthesis of an urease (ureAEFG) were also up-regulated. Down-regulated genes after growth in BHI-B mostly belonged to the "transport and binding proteins", "cell envelope", "protein synthesis" and "hypothetical/ 

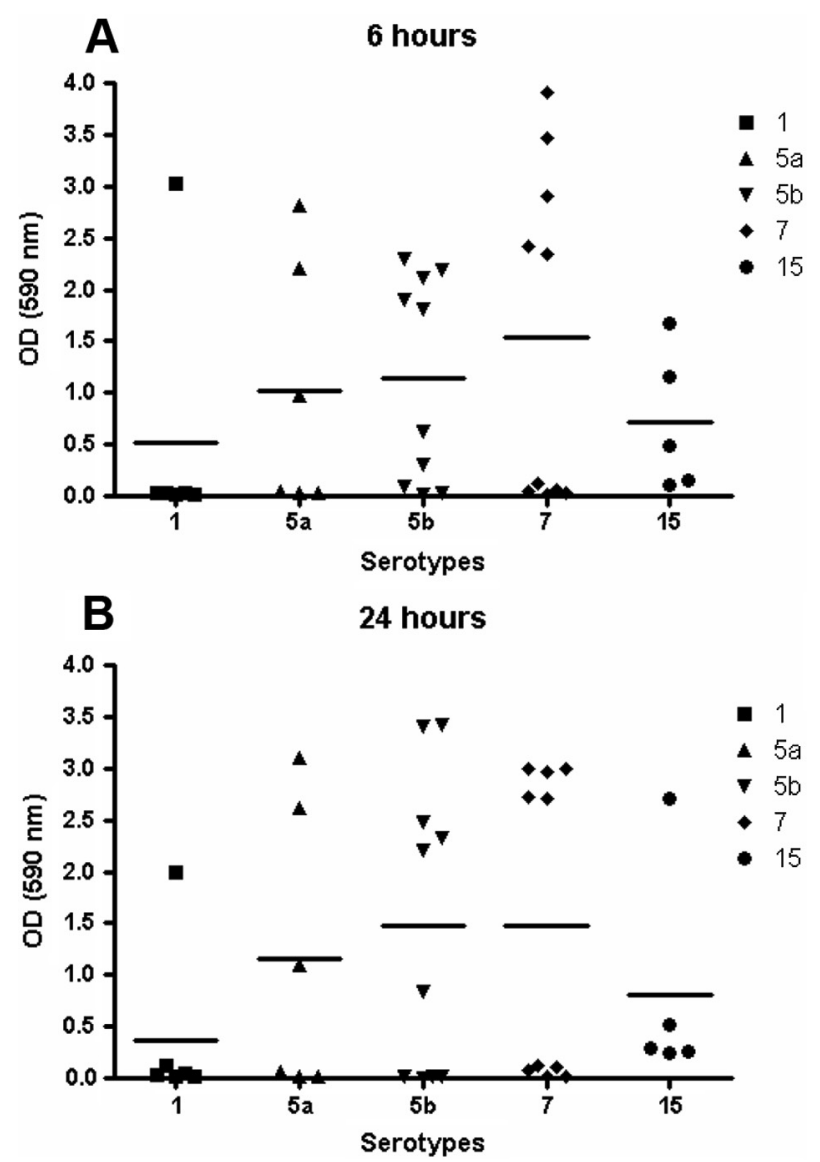

Figure 2. Thirty-seven independent fresh field isolates of $A$. pleuropneumoniae (representing serotypes 1, 5,7 and 15) were tested for their ability to form biofilms when grown for $6 \mathrm{~h}$ (A) and $24 \mathrm{~h}$ (B) in BHI-B using the microtiter plate assay.

unknown/unclassified" functional classes. Most notably, cys genes involved in sulphate transport systems were down-regulated, as well as a gene (APL_1096) sharing 59\% identity with the DspB gene of A. actinomycetemcomitans.

\subsection{Effect of DspB on biofilm formation}

Enzymatic treatment with DspB of biofilms of A. pleuropneumoniae strains $\mathrm{S} 4074$ and L20 grown for 6 or $24 \mathrm{~h}$ almost completely dispersed them $(p<0.05)$ confirming the presence of PGA in the biofilm matrix.

\subsection{Effect of zinc on biofilm formation}

Chemical analysis showed differences in some divalent cations concentration between BHI-A (Fe $<0.10 \mathrm{ppm}, \mathrm{Zn} 2.03 \mathrm{ppm}$ ) and BHI-B (Fe 0.10 ppm, Zn 1.75 ppm) while no differences were observed for others $(\mathrm{Ca}, \mathrm{Cu}$, $\mathrm{Mg}, \mathrm{Mn})$. We therefore hypothesized that the difference in biofilm formation observed after growth in BHI-B compared to BHI-A might be due to cations concentration. Since the concentration of zinc was found to be higher in BHI-A (no or slight biofilm) we tested a 


\section{A BHI-A $24 \mathrm{~h}$}
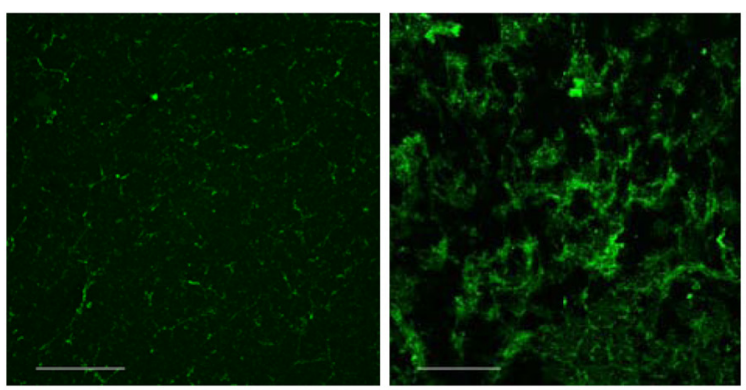

\section{B}
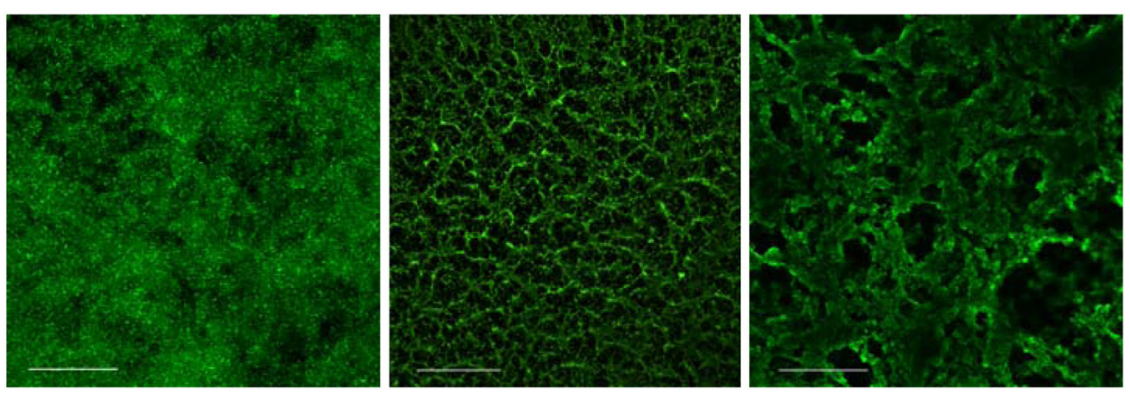

C

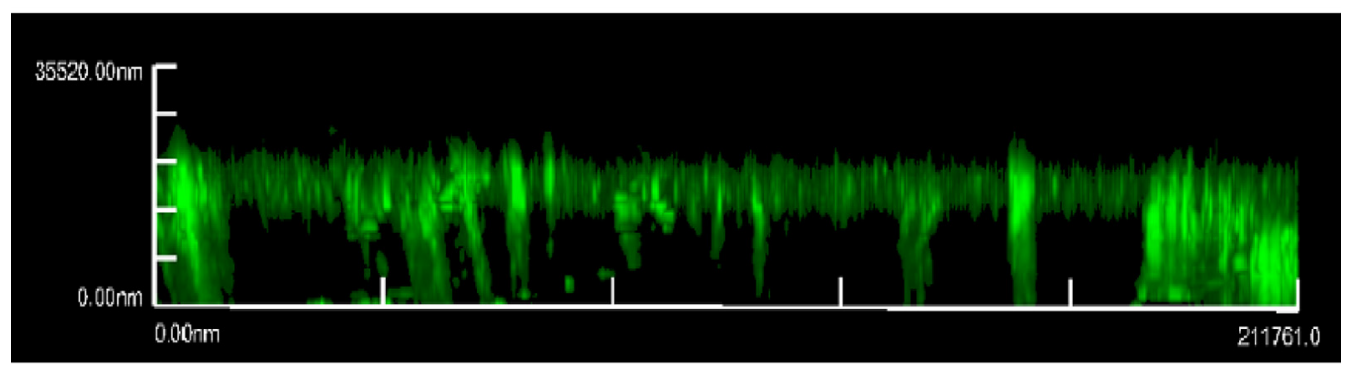

Figure 3. Confocal scanning laser microscopic images of A. pleuropneumoniae serotype 1 strain S4074 (A and C) and serotype 5b strain L20 (B) biofilms stained with WGA-Oregon Green 488. (C) Stack of sections through the $\mathrm{X}-\mathrm{Z}$ plane of a biofilm formed after $6 \mathrm{~h}$ in BHI-B. Bars $=50 \mu \mathrm{m}$.

possible inhibitory effect of this cation on biofilm formation. The addition of $\mathrm{ZnCl}_{2}$ to $\mathrm{BHI}-$ $\mathrm{B}$ inhibited, in a dose-dependent manner, the formation of biofilms by $A$. pleuropneumoniae strains S4074 and L20 (Fig. 5). A complete inhibition $(p<0.01)$ was observed when $100 \mu \mathrm{g} / \mathrm{mL}$ of $\mathrm{ZnCl}_{2}$ was added to $\mathrm{BHI}-\mathrm{B}$, a concentration which did not affect growth after $24 \mathrm{~h}$ (data not shown). A similar inhibition was also observed with the addition of $\mathrm{ZnSO}_{4}$, $\mathrm{ZnO}$, and $\mathrm{Zn}_{3}\left(\mathrm{PO}_{4}\right)_{2}$ but not with $\mathrm{MgCl}_{2}$ or $\mathrm{CaCl}_{2}$ thus confirming that the inhibition was due to the addition of zinc. Biofilm formation in $A$. actinomycetemcomitans was also inhibited 
Table II. A pleuropneumoniae strain S4074 genes that are up- or down-regulated after growth in BHI-B compared to growth in BHI-A.

\begin{tabular}{|c|c|c|c|}
\hline Locus tag & Gene & Description & Fold change \\
\hline \multicolumn{4}{|c|}{ Amino acid biosynthesis } \\
\hline APL_0728 & $i l v H$ & Acetolactate synthase small subunit & 5.707 \\
\hline APL_0662 & $\operatorname{aspC}$ & Putative aspartate aminotransferase & 5.324 \\
\hline APL_0427 & gdhA & NADP-specific glutamate dehydrogenase & 4.943 \\
\hline APL_0727 & $i l v I$ & Acetolactate synthase large subunit & 4.204 \\
\hline APL_0099 & $i l v G$ & Acetolactate synthase isozyme II large subunit (AHAS-II) & 3.915 \\
\hline APL_1499 & thrC & Threonine synthase & 3.198 \\
\hline $\mathrm{APL}^{-} 0097$ & $i l v D$ & Dihydroxy-acid dehydratase & 3.142 \\
\hline $\mathrm{APL}^{-} 0393$ & $\operatorname{leu} A$ & 2-isopropylmalate synthase & 3.000 \\
\hline APL_0098 & $i l v M$ & Acetolactate synthase isozyme II small subunit (AHAS-II) & 2.934 \\
\hline APL_2027 & hisF & Imidazole glycerol phosphate synthase subunit hisF & 2.833 \\
\hline APL_0702 & $\operatorname{ser} C$ & Phosphoserine aminotransferase & 2.788 \\
\hline APL 0432 & leuB & 3-isopropylmalate dehydrogenase & 2.643 \\
\hline APL_0899 & dapA & Dihydrodipicolinate synthase & 2.401 \\
\hline APL_0211 & glyA & Glycine/serine hydroxymethyltransferase & 2.398 \\
\hline APL_0133 & $\operatorname{cys} B$ & HTH-type transcriptional regulator $\mathrm{CysB}$ & 2.340 \\
\hline $\mathrm{APL}_{-}^{-} 1853$ & $i l v C$ & Ketol-acid reductoisomerase & 2.313 \\
\hline APL_0072 & $i l v E$ & Branched-chain-amino-acid aminotransferase & 2.001 \\
\hline APL_0859 & $\operatorname{trp} C F$ & Tryptophan biosynthesis protein trpCF & 1.883 \\
\hline APL_2025 & hisH & Imidazole glycerol phosphate synthase subunit hisH & 1.777 \\
\hline APL_2026 & his $A$ & $\begin{array}{l}\text { Phosphoribosylformimino-5-aminoimidazole carboxamide } \\
\text { ribotide isomerase }\end{array}$ & 1.739 \\
\hline APL_1198 & $A P L \_1198$ & Putative NAD $(\mathrm{P}) \mathrm{H}$ nitroreductase & 1.708 \\
\hline APL 0139 & leu C & 3 -isopropylmalate dehydratase large subunit 2 & 1.605 \\
\hline APL_1230 & $\operatorname{ser} B$ & Phosphoserine phosphatase & 1.438 \\
\hline APL_0620 & aroG & Phospho-2-dehydro-3-deoxyheptonate aldolase & 1.428 \\
\hline APL_1873 & dapE & Succinyl-diaminopimelate desuccinylase & 1.380 \\
\hline \multicolumn{4}{|c|}{ Biosynthesis of cofactors, prosthetic groups, and carriers } \\
\hline APL 0207 & Dxs & 1-deoxy-D-xylulose-5-phosphate synthase (DXPS) & -1.555 \\
\hline APL 1461 & menA & 1,4-dihydroxy-2-naphthoateoctaprenyltransferase & -1.631 \\
\hline APL 0382 & $r i b D$ & Riboflavin biosynthesis protein & -1.726 \\
\hline APL_1408 & $g \operatorname{sh} A$ & Glutathione biosynthesis bifunctional protein GshAB & -1.789 \\
\hline \multicolumn{4}{|c|}{ Cell envelope } \\
\hline APL 1494 & $f t p A$ & Fine tangled pili major subunit & 5.705 \\
\hline APL 1921 & pgaA & Biofilm PGA synthesis protein PgaA precursor & 5.308 \\
\hline APL 0460 & plpD & Lipoprotein Plp4 & 3.801 \\
\hline APL_1923 & pgaC & Biofilm PGA synthesis N-glycosyltransferase PgaC & 3.591 \\
\hline APL_1922 & pgaB & Biofilm PGA synthesis lipoprotein PgaB precursor & 3.093 \\
\hline APL 0006 & отрР $2 A$ & Outer membrane protein $\mathrm{P} 2$ & 2.515 \\
\hline APL_0550 & $\operatorname{tad} C$ & Tight adherence protein $\mathrm{C}$ & 1.985 \\
\hline APL_0442 & $\operatorname{san} A$ & SanA protein & 1.776 \\
\hline APL_0549 & $\operatorname{tad} D$ & Tight adherence protein D & 1.749 \\
\hline APL_0332 & $h l p B$ & Lipoprotein HlpB & 1.627 \\
\hline APL_1364 & $\operatorname{gmh} A$ & Putative phosphoheptose isomerase & 1.386 \\
\hline APL_0873 & $r l p B$ & Putative rare lipoprotein B & -1.391 \\
\hline
\end{tabular}


Table II. Continued.

\begin{tabular}{|c|c|c|c|}
\hline Locus tag & Gene & Description & Fold change \\
\hline APL_1028 & $A P L_{-} 1028$ & $\begin{array}{l}\text { Possible lipooligosaccharide } \mathrm{N} \text {-acetylglucosamine } \\
\text { glycosyltransferase }\end{array}$ & -1.445 \\
\hline APL_0747 & тер $A$ & Penicillin-insensitive murein endopeptidase precursor & -1.446 \\
\hline APL_0436 & mreC & Rod shape-determining protein MreC & -1.585 \\
\hline APL_1086 & ompW & Outer membrane protein $\mathrm{W}$ precursor & -1.606 \\
\hline APL_1029 & $A P L \_1029$ & Hypothetical protein & -1.650 \\
\hline APL_1424 & oxaA & Inner membrane protein $\mathrm{OxaA}$ & -1.772 \\
\hline APL_0933 & ompPl & Putative outer membrane protein precursor & -2.808 \\
\hline \multicolumn{4}{|c|}{ Cellular processes } \\
\hline APL_1489 & $T p x$ & Putative thiol peroxidase & 2.252 \\
\hline APL_0988 & $h k t E$ & Catalase & -1.461 \\
\hline APL_0669 & $A P L \_0669$ & Putative iron dependent peroxidase & -1.483 \\
\hline APL_1442 & apxID & RTX-I toxin secretion component & -1.506 \\
\hline APL_1346 & $f t s Y$ & Cell division protein FtsY-like protein & -1.530 \\
\hline \multicolumn{4}{|c|}{ Central intermediary metabolism } \\
\hline APL_1615 & Gst & Putative glutathione S-transferase & 3.269 \\
\hline APL_1614 & ureE & Urease accessory protein UreE & 2.601 \\
\hline APL_1613 & ureF & Urease accessory protein UreF & 2.478 \\
\hline APL_1612 & ureG & Urease accessory protein UreG & 2.165 \\
\hline APL_1618 & ureA & Urease gamma subunit UreA & 1.653 \\
\hline \multicolumn{4}{|c|}{ DNA metabolism } \\
\hline APL_1931 & $\operatorname{tag} I$ & 3-methyladenine-DNA glycosidase & -1.500 \\
\hline APL_1474 & $\operatorname{dna} G$ & DNA primase & -1.551 \\
\hline APL_1282 & $d n a Q$ & DNA polymerase III subunit & -1.579 \\
\hline $\mathrm{APL}_{-}^{-} 1255$ & parE & DNA topoisomerase IV subunit & -1.630 \\
\hline APL_1505 & holC & DNA polymerase III subunit & -1.663 \\
\hline \multicolumn{4}{|c|}{ Energy metabolism } \\
\hline APL_1197 & $A P L \_1197$ & 3-hydroxyacid dehydrogenase & 3.100 \\
\hline APL_0841 & $\overline{p n t} B$ & $\mathrm{NAD}(\mathrm{P})$ transhydrogenase subunit beta & 2.726 \\
\hline APL_1908 & xylA & Xylose isomerase & 2.243 \\
\hline APL_0894 & $f d x H$ & Formate dehydrogenase, iron-sulfur subunit & 2.161 \\
\hline APL_1425 & napC & Cytochrome c-type protein NapC & 2.159 \\
\hline APL_1799 & $\operatorname{tor} C$ & Pentahemic c-type cytochrome & 2.156 \\
\hline APL_0892 & $f d x G$ & Formate dehydrogenase, nitrate-inducible, major subunit & 2.116 \\
\hline APL_1798 & tor $A$ & Trimethylamine-N-oxide reductase precursor & 1.977 \\
\hline APL_0381 & $g l p C$ & Anaerobic glycerol-3-phosphate dehydrogenase subunit $\mathrm{C}$ & 1.919 \\
\hline APL_0842 & pntA & $\mathrm{NAD}(\mathrm{P})$ transhydrogenase subunit alpha & 1.903 \\
\hline APL_0895 & $f d n I$ & Formate dehydrogenase, cytochrome b556 subunit & 1.816 \\
\hline APL_1208 & $a d h C$ & Putative alcohol dehydrogenase class 3 & 1.801 \\
\hline APL_0971 & APL_0971 & Putative acyl CoA thioester hydrolase & 1.796 \\
\hline APL_0652 & $\operatorname{man} B$ & Phosphomannomutase & 1.677 \\
\hline APL_0483 & $A P L \_0483$ & Predicted nitroreductase & 1.668 \\
\hline APL_0142 & $g \bar{l} x K$ & Glycerate kinase & 1.564 \\
\hline APL_0452 & sucC & Succinyl-CoA synthetase beta chain & 1.515 \\
\hline APL_0461 & $A P L \_0461$ & Predicted hydrolases of the HAD superfamily & 1.456 \\
\hline
\end{tabular}


Table II. Continued.

\begin{tabular}{lccc}
\hline Locus tag & Gene & Description & Fold change \\
\hline APL_0687 & Dld & D-lactate dehydrogenase & 1.439 \\
APL_1510 & $g p s A$ & Glycerol-3-phosphate dehydrogenase (NAD(P)+) & 1.414 \\
APL_1427 & $n a p H$ & Ferredoxin-type protein NapH-like protein & 1.360 \\
APL_0789 & $A P L \_0789$ & Dioxygenase & 1.253 \\
APL_0983 & $t k t A$ & Transketolase 2 & 1.233 \\
APL_1036 & $p f l B$ & Formate acetyltransferase & -1.653 \\
APL_1498 & $m g s A$ & Methylglyoxal synthase & -1.790 \\
APL_1840 & $u b i C$ & 4-hydroxybenzoate synthetase (chorismate lyase) & -1.952 \\
APL_0857 & $s d a A$ & L-serine dehydratase & -3.016
\end{tabular}

Fatty acid and phospholipid metabolism

$\begin{array}{lccc}\text { APL_1407 } & P s d & \text { Phosphatidylserine decarboxylase } & -1.419 \\ \text { APL_1384 } & f a b H & \text { 3-oxoacyl-[acyl-carrier-protein] synthase 3 } & -1.826 \\ \text { APL_1385 } & p l s X & \text { Fatty acid/phospholipid synthesis protein PlsX } & -2.706\end{array}$

Mobile and extrachromosomal element functions
APL_1056
APL_1056
APL_0985
APL_0985
Transposase
Transposase

Protein fate

$\begin{array}{ll}\text { APL_0871 } & \text { pepE } \\ \text { APL_1101 } & \text { pepA } \\ \text { APL_0254 } & \text { pepD } \\ \text { APL_1883 } & \text { ptrA } \\ \text { APL_0928 } & \text { hscB } \\ \text { APL_1068 } & \text { secF } \\ \text { APL_0321 } & d s b B \\ \text { APL_1035 } & \text { pflA }\end{array}$

Protein synthesis

\begin{tabular}{|c|c|c|c|}
\hline APL_1821 & rpmE & 50 S ribosomal protein $\mathrm{L} 31$ & 2.211 \\
\hline APL_0484 & $\operatorname{rim} K$ & Ribosomal protein S6 modification protein & 1.533 \\
\hline APL_1781 & $\operatorname{rps} M$ & $30 \mathrm{~S}$ ribosomal protein $\mathrm{S} 13$ & -1.401 \\
\hline APL_0205 & $A P L \_0205$ & Predicted rRNA methyltransferase & -1.538 \\
\hline APL_0399 & $k \operatorname{sg} A$ & Dimethyladenosine transferase & -1.578 \\
\hline APL_0679 & $g \ln S$ & Glutaminyl-tRNA synthetase & -1.584 \\
\hline APL_0641 & $\operatorname{tru} B$ & tRNA pseudouridine synthase B & -1.742 \\
\hline APL_1383 & $\operatorname{trm} B$ & tRNA (guanine-N(7)-)-methyltransferase & -1.756 \\
\hline APL_0574 & $A P L \_0574$ & tRNA-specific adenosine deaminase & -1.778 \\
\hline APL_0723 & $\operatorname{Tgt}$ & Queuine tRNA-ribosyltransferase & -1.937 \\
\hline
\end{tabular}

Purines, pyrimidines, nucleosides, and nucleotides

$\begin{array}{lccc}\text { APL_0958 } & \text { purH } & \text { Bifunctional purine biosynthesis protein PurH } & 1.856 \\ \text { APL_0593 } & \text { guaB } & \text { Inosine-5'-monophosphate dehydrogenase } & 1.485 \\ \text { APL_1343 } & C d d & \text { Cytidine deaminase } & 1.278 \\ \text { APL_1014 } & \text { deoD } & \text { Purine nucleoside phosphorylase DeoD-like protein } & -1.430 \\ \text { APL_0351 } & N d k & \text { Nucleoside diphosphate kinase } & -1.531 \\ \text { APL_1839 } & U d p & \text { Uridine phosphorylase } & -1.617 \\ \text { APL_1075 } & \text { purA } & \text { Adenylosuccinate synthetase } & -1.762\end{array}$


Table II. Continued.

\begin{tabular}{|c|c|c|c|}
\hline Locus tag & Gene & Description & Fold change \\
\hline \multicolumn{4}{|c|}{ Regulatory functions } \\
\hline APL_0059 & narP & Nitrate/nitrite response regulator protein & 2.552 \\
\hline APL_0823 & $g l p R$ & Glycerol-3-phosphate regulon repressor & 1.908 \\
\hline APL_1295 & $\arg R$ & Arginine repressor & 1.896 \\
\hline APL_0126 & $A P L \_0126$ & HIT-like protein & 1.580 \\
\hline APL_0395 & $r \overline{s e} A$ & Putative sigma-E factor negative regulatory protein & 1.524 \\
\hline APL_1668 & $r b s R$ & Ribose operon repressor & 1.302 \\
\hline APL_1270 & $\operatorname{spr} T$ & Putative SprT-like protein & -1.483 \\
\hline APL_1233 & malT & HTH-type transcriptional regulator MalT & -1.484 \\
\hline $\mathrm{APL}_{-}^{-} 1540$ & $\operatorname{tld} D$ & TldD-like protein & -1.578 \\
\hline \multicolumn{4}{|c|}{ Transcription } \\
\hline APL_0560 & $r h l B$ & ATP-dependent RNA helicase RhlB & 1.409 \\
\hline APL_0423 & $r n h A$ & Ribonuclease HI & 1.345 \\
\hline APL_0201 & $n u s B$ & Transcription antitermination protein NusB & -1.457 \\
\hline \multicolumn{4}{|c|}{ Transport and binding proteins } \\
\hline APL_0967 & gltS & Sodium/glutamate symport carrier protein & 4.155 \\
\hline APL_0377 & $g l p T$ & Glycerol-3-phosphate transporter & 3.247 \\
\hline APL_0064 & dppA & Periplasmic dipeptide transport protein & 3.168 \\
\hline APL_0869 & $\operatorname{abg} B$ & Aminobenzoyl-glutamate utilization-like protein & 3.004 \\
\hline APL_1857 & merP & Copper chaperone MerP & 2.911 \\
\hline APL_0068 & $d p p F$ & Dipeptide transport ATP-binding protein DppF & 2.860 \\
\hline APL_1665 & gntP_l 1 & Gluconate permease & 2.723 \\
\hline APL_0066 & $d p p \bar{C}$ & Dipeptide transport system permease protein DppC & 2.640 \\
\hline APL_1440 & znuA & High-affinity zinc uptake system protein ZnuA precursor & 2.600 \\
\hline APL_0065 & $d p p B$ & Dipeptide transport system permease protein DppB & 2.229 \\
\hline APL_0067 & $d p p D$ & Dipeptide transport ATP-binding protein DppD & 2.036 \\
\hline APL_1448 & afuC & Ferric $\mathrm{ABC}$ transporter ATP-binding protein & 1.855 \\
\hline APL_1319 & $p t s B$ & PTS system sucrose-specific EIIBC component & 1.744 \\
\hline $\mathrm{APL}_{-}^{-} 1320$ & thiQ & Thiamine transport ATP-binding protein ThiQ & 1.569 \\
\hline APL_1622 & $\operatorname{cbiM}$ & Predicted $\mathrm{ABC}$ transport permease protein $\mathrm{CbiM}$ & 1.433 \\
\hline APL_-1620 & $c b i O$ & Predicted $\mathrm{ABC}$ transport ATP-binding protein $\mathrm{CbiO}$ & 1.417 \\
\hline APL_1173 & pnuC & Nicotinamide mononucleotide transporter & 1.408 \\
\hline APL_0749 & $A P L \_0749$ & Potassium efflux system KefA & -1.436 \\
\hline APL_1212 & tehA & Tellurite resistance protein TehA & -1.543 \\
\hline APL_0716 & APL_0716 & Iron(III) $\mathrm{ABC}$ transporter, permease protein & -1.547 \\
\hline $\mathrm{APL}_{-}^{-} 1253$ & $A P L_{-}^{-} 1253$ & Putative sodium/sulphate transporter & -1.598 \\
\hline $\mathrm{APL}_{-}^{-} 1846$ & cys $T$ & Sulfate transport system permease protein cys T & -1.684 \\
\hline APL_0191 & APL_0191 & Predicted $\mathrm{Na}+$-dependent transporter of the SNF family & -1.751 \\
\hline APL_1083 & $\operatorname{arcD}$ & Putative arginine/ornithine antiporter & -1.786 \\
\hline APL_-2016 & fhuA & Ferrichrome-iron receptor FhuA & -2.031 \\
\hline APL_1847 & cys $W$ & Sulfate transport system permease protein cysW & -2.195 \\
\hline APL_1844 & $\operatorname{cys} N$ & Sulphate adenylate transferase subunit 1 & -2.375 \\
\hline APL_ 1848 & cys $A$ & Sulfate/thiosulfate import ATP-binding protein cysA & -2.401 \\
\hline $\mathrm{APL}_{-}^{-} 1843$ & cys $J$ & $\begin{array}{l}\text { Sulfite reductase [NADPH] flavoprotein } \\
\text { alpha-component }\end{array}$ & -2.757 \\
\hline APL_1127 & $A P L \_1127$ & Predicted $\mathrm{Na}+/$ alanine symporter & -3.402 \\
\hline
\end{tabular}


Table II. Continued.

\begin{tabular}{|c|c|c|c|}
\hline Locus tag & Gene & Description & Fold change \\
\hline \multicolumn{4}{|c|}{ Hypothetical/unknown/unclassified } \\
\hline APL_1100 & $A P L \_1100$ & Hypothetical protein & 3.395 \\
\hline APL_0920 & $A P L \_0920$ & Hypothetical protein & 2.835 \\
\hline APL_1882 & $A P L_{-}^{-} 1882$ & Hypothetical protein & 2.776 \\
\hline APL_1856 & $A P L_{-}^{-} 1856$ & Hypothetical protein & 2.775 \\
\hline APL_1855 & $A P L \_1855$ & Hypothetical protein & 2.763 \\
\hline APL 0443 & $A P L 0443$ & Autotransporter adhesin & 2.762 \\
\hline APL 1252 & $A P L^{-} 1252$ & Hypothetical protein & 2.739 \\
\hline APL_0134 & $A P L \_0134$ & Hypothetical protein & 2.681 \\
\hline APL_0836 & $A P L \_0836$ & Putative transcriptional regulator & 2.661 \\
\hline APL_1588 & $A P L \_1588$ & Predicted TRAP transporter solute receptor & 2.464 \\
\hline APL_1491 & $A P L_{-}^{-} 1491$ & Hypothetical protein & 2.282 \\
\hline APL_0104 & $A P L \_0104$ & Autotransporter adhesin & 2.231 \\
\hline APL_1069 & $\overline{\operatorname{tn} A}$ & Ferritin-like protein 1 & 2.194 \\
\hline APL_1059 & APL_1059 & Hypothetical transposase-like protein & 2.172 \\
\hline APL_1690 & $A P L_{-}^{-} 1690$ & Inner membrane protein & 2.168 \\
\hline APL_0245 & $A P L_{-}^{-} 0245$ & Transferrin binding protein-like solute binding protein & 2.097 \\
\hline APL_1191 & namA & NADPH dehydrogenase & 2.078 \\
\hline APL_1948 & $A P L \_1948$ & Hypothetical protein & 2.061 \\
\hline APL_0870 & $A P L \_0870$ & Putative C4-dicarboxylate transporter & 2.034 \\
\hline APL_0643 & $A P L \_0643$ & Hypothetical protein & 2.029 \\
\hline APL_1743 & $A P L_{-}^{-} 1743$ & Ser/Thr protein phosphatase family protein & 1.999 \\
\hline APL_0426 & $A P L \_0426$ & Hypothetical protein & 1.994 \\
\hline APL_1791 & $A P L_{-}^{-} 1791$ & Putative periplasmic iron/siderophore binding protein & 1.944 \\
\hline APL_0970 & $A P L \_0970$ & Hypothetical protein & 1.908 \\
\hline APL_1070 & $f \operatorname{tn} B$ & Ferritin-like protein 2 & 1.907 \\
\hline APL_1894 & $A P L \_1894$ & Hypothetical protein & 1.907 \\
\hline APL_1374 & $A P L_{-}^{-} 1374$ & Hypothetical protein & 1.803 \\
\hline APL_1206 & $A P L \_1206$ & Plasmid stability-like protein & 1.794 \\
\hline APL_1881 & $A P L \_1881$ & Hypothetical protein & 1.792 \\
\hline APL_0038 & $A P L \_0038$ & Hypothetical protein & 1.730 \\
\hline APL_1355 & $A P L_{-}^{-} 1355$ & Hypothetical protein & 1.716 \\
\hline APL_0471 & $A P L \_0471$ & Hypothetical protein & 1.707 \\
\hline APL_1438 & $A P L_{-} 1438$ & Hypothetical protein & 1.689 \\
\hline APL_1437 & $A P L_{-}^{-} 1437$ & Hypothetical protein & 1.643 \\
\hline APL_1423 & $A P L_{-}^{-} 1423$ & Hypothetical protein & 1.612 \\
\hline APL_0125 & $A P L \_0125$ & Hypothetical protein & 1.608 \\
\hline APL_0096 & $A P L \_0096$ & Zinc transporter family protein ZIP & 1.592 \\
\hline APL_0220 & $A P L \_0220$ & Putative lipoprotein & 1.583 \\
\hline APL_1934 & $A P L_{-} 1934$ & Hypothetical protein & 1.570 \\
\hline APL_1574 & $A P L_{-}^{-} 1574$ & Hypothetical protein & 1.543 \\
\hline APL_0036 & $A P L_{-}^{-} 0036$ & Hypothetical protein & 1.533 \\
\hline APL_0222 & $A P L_{-}^{-} 0222$ & Putative lipoprotein & 1.518 \\
\hline APL_1088 & APL_1088 & Hypothetical protein & 1.512 \\
\hline APL_1207 & $A P L \_1207$ & Hypothetical protein & 1.510 \\
\hline APL_0463 & $A P L \_0463$ & Predicted sortase and related acyltransferases & 1.448 \\
\hline APL_1859 & $A P L_{-}^{-} 1859$ & Probable NADH-dependent butanol dehydrogenase 1 & 1.448 \\
\hline APL_1828 & $A P L_{-}^{-} 1828$ & PilT protein-like protein & 1.447 \\
\hline
\end{tabular}


Table II. Continued.

\begin{tabular}{|c|c|c|c|}
\hline Locus tag & Gene & Description & Fold change \\
\hline APL_0433 & $m s r B$ & Methionine sulfoxide reductase B & 1.415 \\
\hline APL_1189 & $A P L \_1189$ & Hypothetical protein & 1.393 \\
\hline APL_0090 & $A P L \_0090$ & Hypothetical protein & 1.360 \\
\hline APL_1709 & $A P L_{-}^{-} 1709$ & Hypothetical protein & -1.307 \\
\hline APL_0357 & $A P L \_0357$ & Hypothetical protein & -1.328 \\
\hline APL_1380 & $A P L_{-}^{-} 1380$ & Hypothetical protein & -1.394 \\
\hline APL_1729 & $A P L_{-}^{-} 1729$ & Hypothetical protein & -1.401 \\
\hline $\mathrm{APL}_{-}^{-} 1062$ & $A P L_{-}^{-} 1062$ & Hypothetical protein & -1.468 \\
\hline APL_0179 & $A P L \_0179$ & Hypothetical protein & -1.481 \\
\hline APL_0940 & $A P L \_0940$ & Hypothetical protein & -1.482 \\
\hline $\mathrm{APL}_{-} 1273$ & $A P L_{-}^{-} 1273$ & $\begin{array}{l}\text { Putative fimbrial biogenesis and twitching motility protein } \\
\text { PilF-like protein }\end{array}$ & -1.488 \\
\hline APL_1131 & $A P L_{-} 1131$ & Hypothetical protein & -1.540 \\
\hline APL_0583 & $A P L \_0583$ & Hypothetical protein & -1.585 \\
\hline APL_1096 & $A P L \_1096$ & Hypothetical protein (59\% ID dispersine B) & -1.594 \\
\hline APL_0936 & $A P L \_0936$ & Hypothetical protein & -1.616 \\
\hline APL_1115 & $A P L_{-}^{-} 1115$ & Hypothetical protein & -1.639 \\
\hline APL_0811 & $A P L_{-}^{-} 0811$ & Hypothetical protein & -1.682 \\
\hline APL_1898 & ap 2029 & Hypothetical protein & -1.798 \\
\hline APL_1654 & $\operatorname{gid} B$ & Methyltransferase GidB & -1.816 \\
\hline APL_0340 & $A P L \_0340$ & Hypothetical protein & -1.893 \\
\hline APL_1381 & $A P L_{-}^{-} 1381$ & Hypothetical protein & -1.926 \\
\hline APL_0053 & typ $A$ & GTP-binding protein & -2.043 \\
\hline APL_1681 & $A P L \_1681$ & Hypothetical protein & -2.233 \\
\hline
\end{tabular}

by zinc (data not shown). Interestingly, genes potentially involved in zinc transport (znuA and APL_0096) were up-regulated after growth in BHI-B (Tab. II).

\section{DISCUSSION}

Biofilm formation is an important virulence trait of many bacterial pathogens including A. pleuropneumoniae. It has been previously reported that only 2 of the $15 \mathrm{~A}$. pleuropneumoniae reference strains, representing serotypes $5 \mathrm{~b}$ and 11 , were able to form a biofilm in vitro [21]. We observed however an increased stickiness of colonies when strain A. pleuropneumoniae S4074 was grown on plates made of BHI from one of two different suppliers. In addition, Li et al. [24] recently observed slight biomass of biofilm when the A. pleuropneumoniae serotype 1 reference strain $\mathrm{S} 4074$ was grown in serum-free TSB and that an enhanced biofilm formation was observed in luxS [24] and hns [8] mutants of A. pleuropneumoniae S4074. These observations brought us to re-evaluate biofilm formation by strain $A$. pleuropneumoniae S4074 under different growth conditions using a standard microtiter plate and crystal violet staining protocol. Our data indicate that strain S4074 has the ability to form a pronounced biofilm when grown in the appropriate conditions, and that the biofilm was sensitive to DspB treatment and can be inhibited by zinc. Transition from a biofilm-positive to a biofilm-negative phenotype is not irreversible in contrast to what was reported by Kaplan and Mulks [21] under different conditions.

Transcript profiling experiments using DNA microarrays indicated that overall, 232 genes were significantly differentially expressed during growth in BHI-B. Genes such as tadC, $\operatorname{tad} D$, genes with homology to autotransporter adhesins as well as genes pgaABC involved in PGA biosynthesis were up-regulated after 


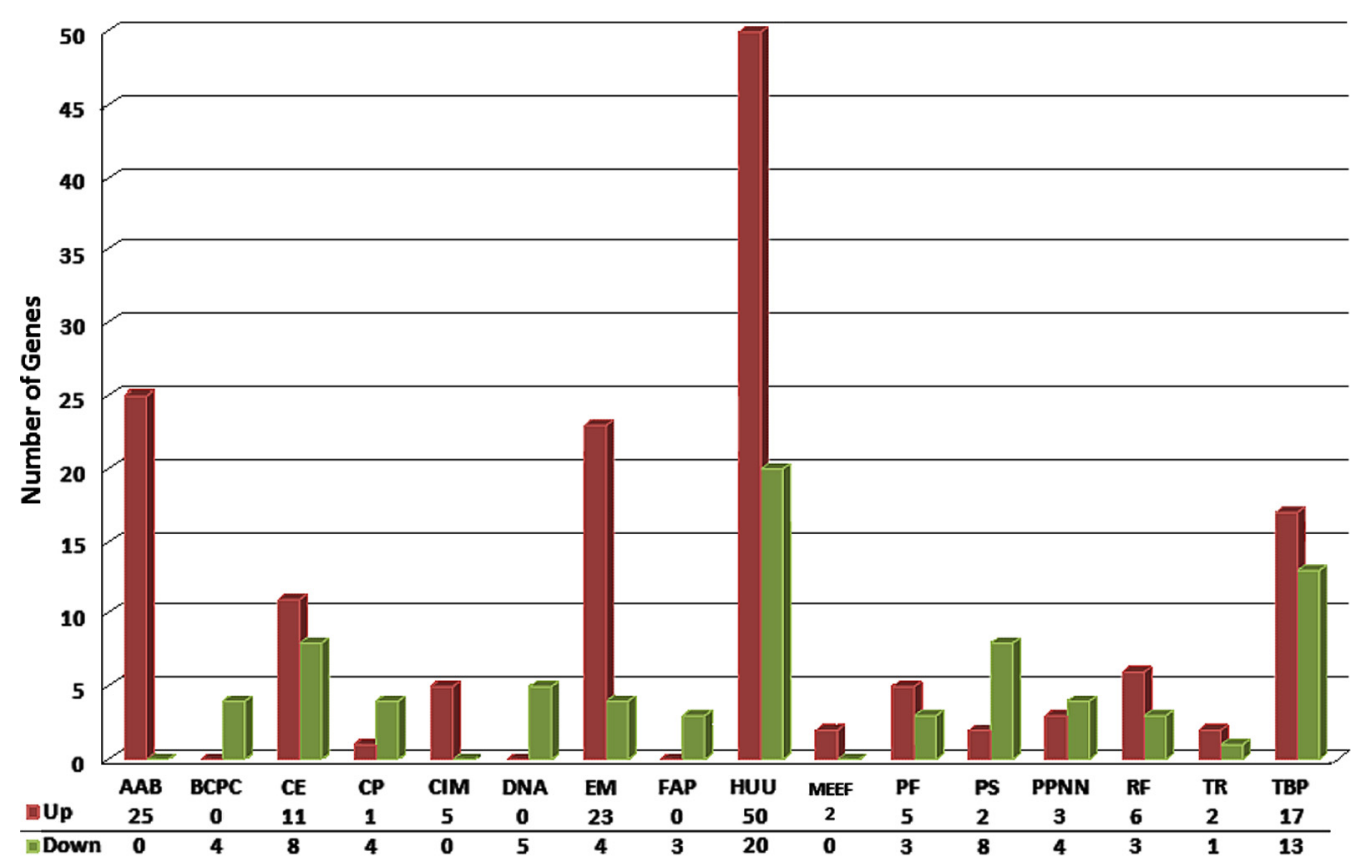

Figure 4. Functional classification of the differentially expressed genes during growth of A. pleuropneumoniae S4074 in BHI-B according to TIGRFAM. AAB: amino acids biosynthesis; BCPC: biosynthesis of cofactors, prosthetic groups and carriers; $\mathrm{CE}$ : cell envelope; $\mathrm{CP}$ : cellular processes; CIM: central intermediary metabolism; DNA: DNA metabolism; EM: energy metabolism; FAPM: fatty acid and phospholipid metabolism; HUU: hypothetical proteins/unclassified/unknown; MEEF: mobile and extrachromosomal element functions; PF: protein fate; PS: protein synthesis; PPNN: purines, pyrimidines, nucleosides and nucleotides; RF: regulatory functions; TR: transcription and TBP: transport and binding proteins.

growth in BHI-B. While we can hypothesize that these genes might be important for the formation of the biofilm itself, it is also interesting to note that many of the same genes $\operatorname{tadB}$, rсpA, gene APL_0443 with high homology to the Hsf autotransporter adhesin of Haemophilus influenzae as well as genes pgaBC involved in biofilm biosynthesis) were up-regulated, when the transcriptomic profile of A. pleuropneumoniae was determined after contact with porcine lung epithelial cells [1], thus emphasizing the possible importance of biofilm formation for the establishment of the infection.

Initial steps in biofilm development require the transcription, early on, of genes involved in reversible attachment and motility, before a subsequent switch towards the transcription of genes involved in the irreversible attachment of bacteria [35]. This second irreversible attachment might require the synthesis of adhesive organelles, such as the curli fibers (csg genes). Interestingly, gene APL_0220 is a putative lipoprotein of the $\mathrm{CsgG}$ family, responsible for the transport and assembly of curli fibers. The up-regulation of other genes possibly involved in adhesion processes (tadC, tadD, Hsf homo$\log$ APL_0443) might indicate that bacterial cells were entering or in the middle of this irreversible attachment phase. In A. actinomycetemcomitans, the Tad locus is essential for biofilm formation [32]. The fact that the transcription of a zinc-specific transporter (znuA) was increased, combined with the decrease in transcription of an hypothetical Zn-dependant 


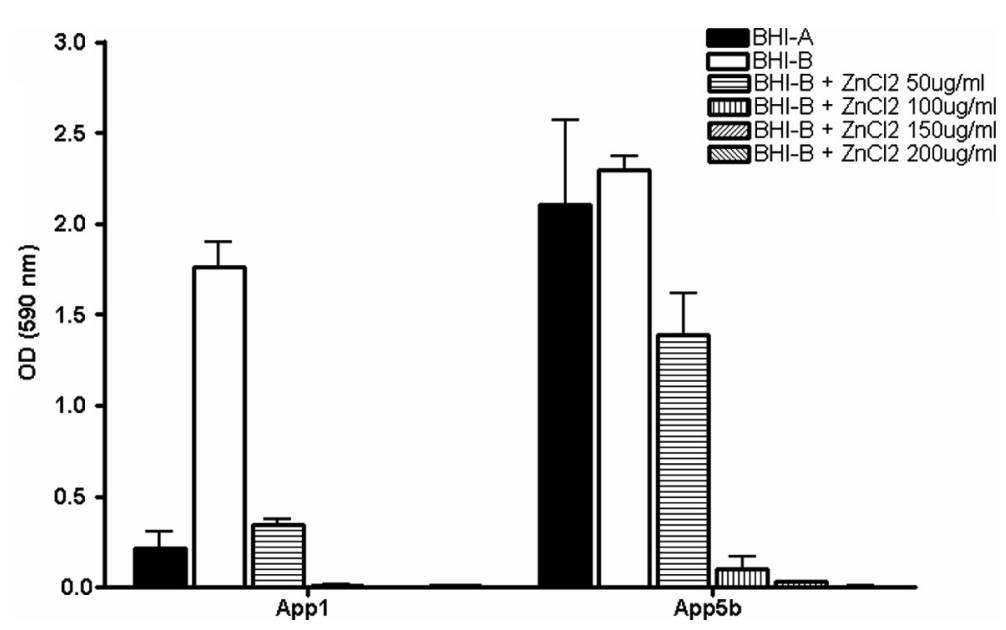

Figure 5. Effect of the addition of $\mathrm{ZnCl}_{2}$ on biofilm formation by A. pleuropneumoniae serotype 1 strain S4074 (App1) and serotype 5b strain L20 (App5b) grown for $6 \mathrm{~h}$.

protease (APL_1898) and lower concentration of this metal in BHI-B lead us to believe that $\mathrm{Zn}$ restriction might be a signal leading to increase biofilm formation.

It is tempting to speculate that growth in BHI-B affected the expression of regulators which in turn affected PGA expression and biofilm formation. Indeed, it has been recently shown that an enhanced biofilm formation was observed in a hns mutant of $A$. pleuropneumoniae strain S4074 [8] and that over-expression of RpoE in a rseA mutant is sufficient to alleviate repression of biofilm formation by H-NS ${ }^{1}$. However, other genes have been shown to affect biofilm formation in A. pleuropneumoniae. An enhanced biofilm formation was observed in a quorum sensing (luxS) mutant [24] while a mutant in the ArcAB two-component system facilitating metabolic adaptation to anaerobicity $(\operatorname{arc} A)$ [5] and an autotransporter

\footnotetext{
${ }^{1}$ Bosse J.T., Sinha S., O'Dwyer C.A., Rycroft A.N., Kroll J.S., Langford P.R., H-NS is a specific regulator of biofilm formation in Actinobacillus pleuropneumoniae, Proceedings of the International Pasteurellaceae Society meeting, Sorrento, Italy, 2008, p. 110.
}

serine protease (AasP) mutant were deficient in biofilm formation [31]. It is interesting to note that many genes involved in branchedchain amino acid biosynthesis (ilv genes) were up-regulated after growth in BHI-B. Limitation of branched-chain amino acids was shown to be a cue for expression of a subset of in vivo induced genes in A. pleuropneumoniae, including not only genes involved in the biosynthesis of branched-chain amino acids, but also other genes that are induced during infection of the natural host [34].

Our data indicate that many strains of A. pleuropneumoniae have the ability to form biofilms under appropriate growth conditions. This is an important observation considering that $A$. pleuropneumoniae biofilm cells exhibit increased resistance to antibiotics compared to planktonic cells [17] and may also exhibit increased resistance to biocides [12]. Biofilms are often associated with chronic infections but the fact that $A$. pleuropneumoniae can form an important biofilm after only $6 \mathrm{~h}$ of incubation suggests that biofilm formation might also play a role in acute infections.

We have undertaken the screen of a large library of mini-Tn10 isogenic mutants of A. pleuropneumoniae $\mathrm{S} 4074$ in order to identify other genes that are involved in biofilm 
formation and/or regulation. A better understanding of biofilm formation in A. pleuropneumoniae might lead to the development of molecules or strategies to interfere with biofilm formation and prevent infection in pigs. In that respect, we made an important, and unexpected, observation that zinc could completely inhibit biofilm formation in A. pleuropneumoniae and A. actinomycetemcomitans, which also synthesizes PGA [20]. We do not know at this time how zinc interferes with PGA biosynthesis and biofilm formation but some glycosyltransferases have been shown to be inhibited by zinc [23]. Hypozincemia which occurs during infection and inflammation [26] might therefore favour biofilm formation by $A$. pleuropneumoniae. Knowing that PGA functions as a biofilm matrix polysaccharide in phylogenetically diverse bacterial species such as Staphylococcus aureus, S. epidermidis, and Escherichia coli [20], it would be worth investigating whether zinc can also interfere with PGA biosynthesis in these other bacterial pathogens.

Acknowledgements. This work was supported by a discovery grant from the Natural Sciences and Engineering Research Council of Canada (DGPIN0003428) to M. Jacques. The authors would also like to acknowledge the contribution of Patrick Vincent for confocal microscopy.

\section{REFERENCES}

[1] Auger E., Deslandes V., Ramjeet M., Contreras I., Nash J.H., Harel J., et al., Host pathogen interactions of Actinobacillus pleuropneumoniae with porcine lung and tracheal epithelial cells, Infect. Immun. (2009) 77:1426-1441.

[2] Bernstein J.A., Khodursky A.B., Lin P.H., Lin-Chao S., Cohen S.N., Global analysis of mRNA decay and abundance in Escherichia coli at singlegene resolution using two-color fluorescent DNA microarrays, Proc. Natl. Acad. Sci. USA (2002) 99:9697-9702.

[3] Blackall P.J., Klaasen H.L., van den Bosch H., Kuhnert P., Frey J., Proposal of a new serovar of Actinobacillus pleuropneumoniae: serovar 15, Vet. Microbiol. (2002) 84:47-52.

[4] Bosse J.T., Janson H., Sheehan B.J., Beddek A.J., Rycroft A.N., Kroll J.S., Langford P.R., Actinobacillus pleuropneumoniae: pathobiology and pathogenesis of infection, Microbes Infect. (2002) 4:225-235.

[5] Buettner F.F., Maas A., Gerlach G.-F., An Actinobacillus pleuropneumoniae arcA deletion mutant is attenuated and deficient in biofilm formation, Vet. Microbiol. (2008) 127:106-115.

[6] Carrillo C.D., Taboada E., Nash J.H., Lanthier P., Kelly J., Lau P.C., et al., Genome-wide expression analyses of Campylobacter jejuni NCTC11168 reveals coordinate regulation of motility and virulence by $f h A$, J. Biol. Chem. (2004) 279:20327-20338.

[7] Costerton J.W., Springer series on biofilms: the biofilm primer, Springer-Verlag, Berlin Heidelberg, 2007.

[8] Dalai B., Zhou R., Wan Y., Kang M., Li L., Li T., et al., Histone-like protein H-NS regulates biofilm formation and virulence of Actinobacillus pleuropneumoniae, Microb. Pathog. (2009) 46:128-134.

[9] Deslandes V., Nash J.H., Harel J., Coulton J.W., Jacques M., Transcriptional profiling of Actinobacillus pleuropneumoniae under iron-restricted conditions, BMC Genomics (2007) 8:72.

[10] Dubreuil J.D., Jacques M., Mittal K.R., Gottschalk M., Actinobacillus pleuropneumoniae surface polysaccharides: their role in diagnosis and immunogenicity, Anim. Health Res. Rev. (2000) 1:73-93.

[11] Frey J., RTX toxin-determined virulence in Pasteurellaceae, in: Kuhnert P., Christensen H. (Eds.), Pasteurellaceae - biology, genomics and molecular aspects, Caister Academic Press, Norfolk, UK, 2008, pp. 133-144.

[12] Ganeshnarayan K., Shah S.M., Libera M.R., Santostefano A., Kaplan J.B., Poly-N-acetylglucosamine matrix polysaccharide impedes fluid convection and transport of the cationic surfactant cetylpyridinium chloride through bacterial biofilms, Appl. Environ. Microbiol. (2009) 75:1308-1314.

[13] Gouré J., Findlay W.A., Deslandes V., Bouevitch A., Foote S.J., MacInnes J.I., et al., Microarray-based comparative genomic profiling of reference strains and selected Canadian field isolates of Actinobacillus pleuropneumoniae, BMC Genomics (2009) 10:88.

[14] Haesebrouck F., Chiers K., Van Overbeke I., Ducatelle R., Actinobacillus pleuropneumoniae infections in pigs: the role of virulence factors in pathogenesis and protection, Vet. Microbiol. (1997) 58:239-249.

[15] Hall-Stoodley L., Costerton J.W., Stoodley P., Bacterial biofilms: from the natural environment to infectious diseases, Nat. Rev. Microbiol. (2004) 2: 95-108. 
[16] Inzana T.J., Swords W.E., Sandal I., Siddaramappa S., Lipopolysaccharides, biofilms and quorum sensing in Pasteurellaceae, in: Kuhnert P., Christensen H. (Eds.), Pasteurellaceae - biology, genomics and molecular aspects, Caister Academic Press, Norfolk, UK, 2008, pp. 177-195.

[17] Izano E.A., Sadovskaya I., Vinogradov E., Mulks M.H., Velliyagounder K., Ragunath C., et al., Poly-N-acetylglucosamine mediates biofilm formation and antibiotic resistance in Actinobacillus pleuropneumoniae, Microb. Pathog. (2007) 43:1-9.

[18] Jacques M., Role of lipo-oligosaccharides and lipopolysaccharides in bacterial adherence, Trends Microbiol. (1996) 4:408-409.

[19] Jacques M., Surface polysaccharides and ironuptake systems in Actinobacillus pleuropneumoniae, Can. J. Vet. Res. (2004) 68:81-85.

[20] Kaplan J.B., Velliyagounder K., Ragunath C., Rohde H., Mack D., Knobloch J.K., Ramasubbu N., Genes involved in the synthesis and degradation of matrix polysaccharide in Actinobacillus actinomycetemcomitans and Actinobacillus pleuropneumoniae biofilms, J. Bacteriol. (2004) 186:8213-8220.

[21] Kaplan J.B., Mulks M.H., Biofilm formation is prevalent among field isolates of Actinobacillus pleuropneumoniae, Vet. Microbiol. (2005) 108:89-94.

[22] Kerrigan J.E., Ragunath C., Kandra L., Gyémant G., Liptak A., Janossy L., et al., Modeling and biochemical analysis of the activity of antibiofilm agent Dispersin B, Acta Biol. Hung. (2008) 59: 439-451.

[23] Koo H., Sheng J., Nguyen P.T., Marquis R.E., Co-operative inhibition by fluoride and zinc of glucosyltransferase production and polysaccharide synthesis by mutans streptococci in suspension cultures and biofilms, FEMS Microbiol. Lett. (2006) 254:134-140.

[24] Li L., Zhou R., Li T., Kang M., Wan Y., Xu Z., Chen H., Enhanced biofilm formation and reduced virulence of Actinobacillus pleuropneumoniae luxS mutant, Microb. Pathog. (2008) 45:192-200.

[25] Liu J., Tan C., Li J., Chen H., Xu P., He Q., et al., Characterization of ISAp11, an insertion element from Actinobacillus pleuropneumoniae field isolate in China, Vet. Microbiol. (2008) 132:348-354.
[26] Liuzzi J.P., Lichten L.A., Rivera S., Blanchard R.K., Aydemir T.B., Knutson M.D., et al., Interleukin6 regulateds the zinc transporter Zip 14 in liver and contributes to the hypozincemia of the acute-phase response, Proc. Natl. Acad. Sci. USA (2005) 102:6843-6848.

[27] Merritt J.H., Kadouri D.E., O’Toole G.A., Growing and analyzing static biofilms, Curr. Protoc. Microbiol. (2005) 1B.1.1-1B.1.17.

[28] Ramjeet M., Deslandes V., St Michael F., Cox A.D., Kobisch M., Gottschalk M., Jacques M., Truncation of the lipopolysaccharide outer core affects susceptibility to antimicrobial peptides and virulence of Actinobacillus pleuropneumoniae serotype 1, J. Biol. Chem. (2005) 280:39104-39114.

[29] Ramjeet M., Cox A.D., Hancock M.A., Mourez M., Labrie J., Gottschalk M., Jacques M., Mutation in the lipopolysaccharide outer core biosynthesis gene, galU, affects LPS interaction with the RTX toxins ApxI and ApxII and cytolytic activity of Actinobacillus pleuropneumoniae serotype 1, Mol. Microbiol. (2008) 70:221-235.

[30] Saeed A.I., Sharov V., White J., Li J., Liang W., Bhagabati N., et al., TM4: a free, open-source system for microarray data management and analysis, Biotechniques (2003) 34:374-378.

[31] Tegetmeyer H.E., Fricke K., Baltes N., An isogenic Actinobacillus pleuropneumoniae AasP mutant exhibits altered biofilm formation but retain virulence, Vet. Microbiol. (2009) 137:392-396.

[32] Tomich M., Planet P.J., Figurski D.H., The Tad locus: postcards from the widespread colonization island, Nat. Rev. Microbiol. (2007) 5:363-375.

[33] Tusher V.G., Tibshirani R., Chu G., Significance analysis of microarrays applied to the ionizing radiation response, Proc. Natl. Acad. Sci. USA (2001) 98:5116-5121.

[34] Wagner T.K., Mulks M.H., A subset of Actinobacillus pleuropneumoniae in vivo induced promoters respond to branched-chain amino acids limitation, FEMS Immunol. Med. Microbiol. (2006) 48:192-204.

[35] Wood T.K., Insights on Escherichia coli biofilm formation and inhibition from whole-transcriptome profiling, Environ. Microbiol. (2009) 1:1-15. 